\title{
LETTER
}

\section{Ventilation during extracorporeal membrane oxygenation for adult respiratory distress syndrome}

\author{
Markus Kredel, Dominik Bierbaum, Christopher Lotz, Julian Kuestermann, Norbert Roewer and Ralf M Muellenbach \\ See related review by Schmidt et al., http://ccforum.com/content/18/1/203
}

Lung protective ventilation is the mainstay of treatment in acute respiratory distress syndrome (ARDS). However, in patients who have severe ARDS and who are receiving extracorporeal membrane oxygenation (ECMO), the ventilation strategy might be modified. This was the subject of the review by Schmidt and colleagues [1] in a recent issue of Critical Care. We invited 39 ARDS centers in Germany to participate in a survey about respiratory and adjuvant ARDS therapy. The questionnaire was completed by 25 centers, 22 of which applied ECMO therapy at the specific time point of the survey (2011 to 2012).

The majority of the ARDS/ECMO centers preferred controlled mechanical ventilation during ECMO therapy, and only 14\% favored assisted or spontaneous breathing. During ECMO, peak/plateau pressures and tidal volumes were lowered by $96 \%$ and $91 \%$ of the centers, respectively. The specified minimal and maximal tidal volumes were 2 (1.8 to 3 ) and 6 (4 to 6$) \mathrm{mL} / \mathrm{kg}$ ideal body weight (median and interquartile range), respectively. Positive endexpiratory pressure (PEEP) was determined by using a 'Best-PEEP-Trial' in 50\%, empirical means in $46 \%$, or the ARDS-Network table in 36\%. Pressure volume curves, computed tomography, and electrical impedance tomography, on the other hand, were rarely consulted to determine the optimal PEEP. However, a reduction in PEEP was done by only two institutions. Respiratory rates during ECMO were nearly equally distributed between fewer than 4,4 to 12,13 to 19 , and 20 to 29 breaths per minute. The inspiratory-to-expiratory time ratios were 1:1 in seven and 1:2 in three centers. Inversed ratio (2:1 to 4:1) ventilation was conducted by $14 \%$; only three applied recruitment maneuvers. Sixty-eight percent used $135^{\circ}$ prone positioning, $36 \%$ full prone positioning, and $27 \%$ continuous axial rotation during ECMO therapy. Other strategies, such as the daily interruption of sedation and spontaneous breathing trials, were conducted in $72 \%$ and $86 \%$ of the centers, respectively. Eighteen used specific protocols for the weaning from ECMO. Early tracheostomy was aimed for in $64 \%$ and actually performed within the first 4 days of ECMO therapy in $41 \%$ of the centers.

The current survey shows that mechanical ventilation is frequently altered toward a protective, or even 'ultraprotective', strategy during ECMO. Adjuvant strategies were not limited by the presence of the extracorporeal circuit and remained integral elements of care. Notably, assisted or spontaneous breathing was seldom accomplished, despite daily interruption of sedation, the use of specific weaning protocols, and early tracheostomy. All in all, most centers relied on proven ARDS standards of care, assuming the physiologically most favorable response while randomized controlled trials during ECMO are missing.

\section{Abbreviations}

ARDS: Acute respiratory distress syndrome; ECMO: Extracorporeal membrane oxygenation; PEEP: Positive end-expiratory pressure.

\section{Competing interests}

The authors declare that they have no competing interests.

Published: 30 Jun 2014

\section{Reference}

1. Schmidt M, Pellegrino V, Combes A, Scheinkestel C, Cooper DJ, Hodgson C: Mechanical ventilation during extracorporeal membrane oxygenation. Crit Care 2014, 18:203.

$10.1186 / \mathrm{cc} 13954$

Cite this article as: Kredel et al: Ventilation during extracorporeal membrane oxygenation for adult respiratory distress syndrome. Critical Care 2014, 18:442

* Correspondence: muellenbac_r@ukw.de

Department of Anaesthesia and Critical Care, University of Würzburg,

Oberdürrbacherstr. 6, 97080 Würzburg, Germany

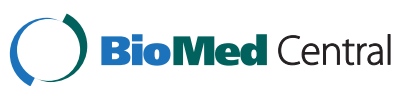

(C) 2014 Kredel et al.; licensee BioMed Central Ltd. This is an Open Access article distributed under the terms of the Creative Commons Attribution License (http://creativecommons.org/licenses/by/4.0), which permits unrestricted use, distribution, and reproduction in any medium, provided the original work is properly credited. The Creative Commons Public Domain Dedication waiver (http://creativecommons.org/publicdomain/zero/1.0/) applies to the data made available in this article, unless otherwise stated. 